\title{
A national analysis of wedge resection versus stereotactic body radiation therapy for stage IA non-small cell lung cancer
}

\author{
Babatunde A. Yerokun, MD, ${ }^{a}$ Chi-Fu Jeffrey Yang, MD, ${ }^{a}$ Brian C. Gulack, MD, ${ }^{a}$ Xuechan Li, MS, ${ }^{b}$ \\ Michael S. Mulvihill, MD, ${ }^{\mathrm{a}}$ Lin Gu, MS, ${ }^{\mathrm{b}}$ Xiaofei Wang, $\mathrm{PhD},{ }^{\mathrm{b}}$ David H. Harpole, MD, \\ Thomas A. D'Amico, MD, ${ }^{a}$ Mark F. Berry, MD, ${ }^{c}$ and Matthew G. Hartwig, MD ${ }^{\mathrm{a}}$
}

\begin{abstract}
Objective: Lobectomy is considered optimal therapy for early-stage non-small cell lung cancer, but sublobar wedge resection and stereotactic body radiation therapy are alternative treatments. This study compared outcomes between wedge resection and stereotactic body radiotherapy.

Methods: Overall survival of patients with cT1N0 and tumors $\leq 2 \mathrm{~cm}$ who underwent stereotactic body radiotherapy or wedge resection in the National Cancer Data Base from 2008 to 2011 was assessed via a Kaplan-Meier and propensity score-matched analysis. A center-level sensitivity analysis that used observed/ expected mortality ratios was conducted to identify an association between center use of stereotactic body radiotherapy and mortality.
\end{abstract}

Results: Of the 6295 patients included, $1778(28.2 \%)$ underwent stereotactic body radiotherapy, and $4517(71.8 \%)$ underwent wedge resection. Stereotactic body radiotherapy was associated with significantly reduced 5-year survival compared with wedge resection in both unmatched analysis (30.9\% vs $55.2 \%$, $P<.001)$ and after adjustment for covariates $(31.0 \%$ vs $49.9 \%, P<.001)$. Stereotactic body radiotherapy also was associated with worse overall survival than wedge resection after 2 subgroup analyses of propensity-matched patients $(P<.05$ for both). Centers that used stereotactic body radiotherapy more often as opposed to surgery for patients with cT1N0 patients with tumors $<2 \mathrm{~cm}$ were more likely to have an observed/expected mortality ratio $>1$ for 3-year mortality $(P=.034)$.

Conclusions: In this national analysis, wedge resection was associated with better survival for stage IA non-small cell lung cancer than stereotactic body radiotherapy. (J Thorac Cardiovasc Surg 2017;154:675-86)

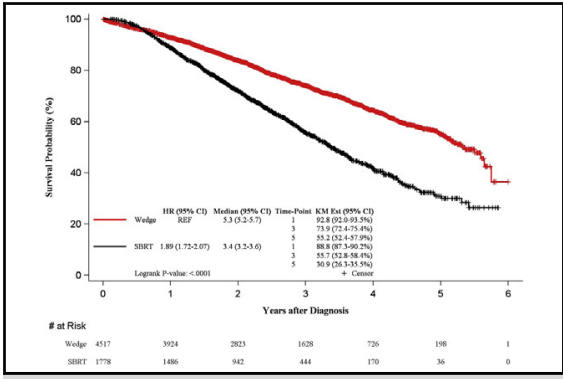

Overall survival for operable patients with clinicalstage IA non-small cell lung cancer.

\section{Central Message}

Stereotactic body radiotherapy is associated with decreased survival compared with wedge resection for patients with clinical-stage IA non-small cell lung cancer.

\section{Perspective}

We compared stereotactic body radiotherapy and wedge resection for patients with clinicalstage IA non-small cell lung cancer using a national database and found a survival advantage associated with wedge resection. These results highlight the need for multidisciplinary involvement in the evaluation of patients with early-stage non-small cell lung cancer.

See Editorial Commentary page 687

\footnotetext{
From the a Division of Cardiovascular and Thoracic Surgery, Department of Surgery, Duke University Medical Center; ${ }^{\mathrm{b}}$ Department of Biostatistics \& Bioinformatics, Duke University School of Medicine, Durham, NC; and ${ }^{c}$ Department of Cardiothoracic Surgery, Stanford University, Stanford, Calif.

B.A.Y. and B.C.G. are supported by the National Institutes of Health-funded Cardiothoracic Surgery Trials Network 5U01HL088953-05.

Read at the 96th Annual Meeting of The American Association for Thoracic Surgery, Baltimore, Maryland, May 14-18, 2016.

Drs Berry and Hartwig are co-senior authors.

Received for publication May 13, 2016; revisions received Jan 8, 2017; accepted for publication Feb 12, 2017; available ahead of print April 29, 2017.

Address for reprints: Matthew G. Hartwig, MD, Duke University Medical Center, Box 3863, Durham, NC 27710 (E-mail: matthew.hartwig@ duke.edu). $0022-5223 / \$ 36.00$

Copyright (c) 2017 by The American Association for Thoracic Surgery http://dx.doi.org/10.1016/j.jtcvs.2017.02.065
}

As implementation of lung cancer screening increases, the percentage of patients with early-stage lung cancer is likely to rise, increasing the opportunity for surgical management. Margin-negative anatomic surgical resection with systematic lymph node evaluation is considered the standard of

Scanning this QR code will take you to supplemental figures for this article. To view the AATS 2016 Webcast, see the URL next to the video thumbnail. 


\section{Abbreviations and Acronyms \\ $\mathrm{CI}=$ confidence Interval \\ JCOG = Japan Clinical Oncology Group \\ $\mathrm{NCDB}=$ National Cancer Data Base \\ NSCLC $=$ non-small cell lung cancer \\ $\mathrm{O} / \mathrm{E}=$ observed to expected \\ ROSEL $=$ Trial of Either Surgery or Stereotactic \\ Radiotherapy for Early Stage (IA) Lung Cancer \\ RTOG = Radiation Therapy Oncology Group \\ SBRT = stereotactic body radiotherapy \\ STARS $=$ Randomized Study to Compare \\ CyberKnife to Surgical Resection In \\ Stage I Non-Small Cell Lung Cancer}

care for early-stage non-small cell lung cancer (NSCLC) in patients who can tolerate surgery. ${ }^{1}$ An operative alternative to anatomic resection includes surgical wedge resection. ${ }^{2,3}$ There are a subset of patients with small, peripheral lesions who are considered high risk for surgery based on their underlying lung function and/or medical comorbidities. Because the impact of wedge resection on lung function is minimal and the physiologic impact of surgery well-tolerated by most patients, these patients were managed, historically, with wedge resection for local control as the only alternative to definitive nonoperative treatments. Over the past decade, however, stereotactic body radiation therapy (SBRT) has been proposed as a viable alternative. ${ }^{4,5}$

Initially, SBRT was used primarily to treat patients with NSCLC deemed inoperable secondary to other medical conditions or poor pulmonary function. SBRT now is also being actively investigated to determine its role in the management of patients who can tolerate surgery, ${ }^{6-8}$ although 3 separate randomized clinical trials have been terminated early secondary to poor accrual..$^{9-11}$ Retrospective single and multi-institutional studies have shown both comparable and improved results with SBRT compared with surgery. ${ }^{12-16}$ However, 2 recent large cohort studies reported decreased survival with SBRT compared with surgical resection, although these studies were not focused on wedge resection and considered larger T2 tumors. ${ }^{17,18}$

Limiting the comparison of SBRT and surgical resection to only surgical wedge resection may be more appropriate than considering all types of surgical resections, considering that both wedge resection and SBRT without additional lymph node sampling essentially limit treatment to only the immediate lung parenchyma in the area of a lung cancer. We hypothesized that surgical resection with wedge resection is associated with better survival than treatment with SBRT. Our study aim was to compare overall survival after management with SBRT and wedge resection in propensity score-matched patients. Unfortunately, a clinical trial that addresses this extremely important management question is unlikely to be completely in the near future, especially considering the multiple failures to complete trials that compare SBRT and surgery as described previously. Therefore, this study was undertaken to test our hypothesis by using the National Cancer Date Base (NCDB) to assemble a large cohort of patients with clinical-stage IA NSCLC who were treated with either wedge resection or SBRT.

\section{MATERIAL AND METHODS National Cancer Data Base}

The Duke University Institutional Review Board approved this retrospective review of the NCDB. The NCDB, established in 1989, is a nationwide, facility-based, comprehensive clinical surveillance resource oncology data set that currently captures $70 \%$ of all newly diagnosed malignancies in the United States annually. The NCDB is administered jointly by the American College of Surgeons and the American Cancer Society and collects data from more than 1500 cancer institutions. The database currently contains data from more than 30 million patient records. The American College of Surgeons has executed a Business Associate Agreement that includes a data use agreement with each of its Commission on Cancer-accredited hospitals. ${ }^{19}$ All patients within the NCDB have histologic confirmation of their cancer diagnosis.

\section{Study Population}

Patients with clinical-stage IA NSCLC were identified by the use of International Classification of Disease for Oncology, 3rd Edition histology and topography codes. The tumor histology codes C34.0-C34.3 and C34.8-C34.9 were used, and those patients who underwent wedge resection or SBRT between 2008 and 2011 were selected for analysis. Patients who received radiation treatment before wedge resection or SBRT were excluded, but preoperative chemotherapy was not an exclusion criteria. We limited our analysis to patients with tumors less than or equal to $2 \mathrm{~cm}$ in accordance with current National Comprehensive Cancer Network guideline recommendations for use of sublobar resection for NSCLC. ${ }^{20}$

\section{Statistical Analysis}

Patients were grouped by whether they underwent SBRT or wedge resection. Wedge resection was the control, whereas SBRT was the exposure. Long-term survival (defined as the date of diagnosis to date of death from any cause and censored at date of most recent alive follow-up that is recorded in the NCDB) was the primary endpoint and was estimated with the Kaplan-Meier method ${ }^{21}$ and compared between treatment modalities by use of the log-rank test and $\chi^{2}$ test. To reduce potential bias from patient selection, treatment group matching was performed with propensity scores. Logistic regression ${ }^{22}$ was used to estimate the corresponding scores from the following covariates: age, sex, race, insurance status, Charlson-Deyo comorbidity score, facility type, histology type, tumor location, tumor size, and distance to hospital. Patients were matched by propensity scores via a 1:1 greedy algorithm. The matching macro used was OneToManyMATCH. ${ }^{23}$ In addition, we performed 2 separate propensity-matched subgroup analyses. To test the hypothesis of whether SBRT compromised survival in elderly patients, a subgroup analysis was performed with patients older than 80 years of age. To test the hypothesis of whether SBRT compromised survival in patients with multiple comorbidities, we performed a subgroup analysis in patients with a Charlson-Deyo comorbidity score of 2 or greater.

To further evaluate whether the results of the main analysis were biased by patients either being treated at centers inexperienced with 
either approach or by being treated at centers that exclusively used one approach, we performed a center-level sensitivity analysis ${ }^{24}$ in which we analyzed the association of center performance (defined as a ratio of observed to expected [O/E] mortality) and the use of SBRT. A multivariate logistic regression model was created to predict mortality incorporating age, sex, race, insurance status, Charlson-Deyo comorbidity score, facility type, histology type, tumor location, tumor size, and distance to hospital. The risk model was then used to calculate the expected mortality for each center.

The observed mortality for each center was divided by the expected mortality to calculate the O/E ratio. Centers with an O/E $>1$ had an increased mortality compared with what was expected given the characteristics of the patients they treated, meaning they performed worse than expected. Conversely, centers with an $\mathrm{O} / \mathrm{E}<1$ had decreased mortality compared with expected, meaning they performed better than expected.

All centers were divided into quartiles based of their percentage use of SBRT as opposed to wedge resection. Centers with all SBRT patients, with all wedge resection patients, or with less than 5 patients were excluded from the analysis to make the analysis generalizable to established centers that perform both SBRT and surgical resection. This was also performed to decrease the bias associated with center-level analyses by decreasing the amount of variability between the centers being compared. The O/E ratios of the centers based off their percent use of SBRT were then compared with each other with the Cochran-Armitage test for trend. Quartiles were compared with the $\chi^{2}$ test. Complete case analysis was used for all adjusted analyses. All analyses were performed using SAS 9.4 (SAS Institute, Cary, NC).

\section{RESULTS}

A total of 6295 patients met study criteria, of whom 1778 $(28.2 \%)$ received SBRT and $4517(71.8 \%)$ received wedge resection (Figure E1). Of the patients who received wedge resection, $528(11.7 \%)$ were upstaged after operation from clinical IA to pathologic IB or greater. The median number of lymph nodes evaluated in the wedge resection group was 3 lymph nodes, and 2051 patients had no lymph nodes examined. In the overall study cohort, $2.8 \%$ and $5.3 \%$ received preprocedural chemotherapy for the SBRT and wedge resection group, respectively.

Patients who received SBRT were more likely to be older and have nonprivate insurance but less likely to

TABLE 1. Overall cohort: unmatched and propensity score-matched patient characteristics

\begin{tabular}{|c|c|c|c|c|c|c|}
\hline & \multicolumn{3}{|c|}{ Unmatched } & \multicolumn{3}{|c|}{ Matched } \\
\hline & SBRT $(n=1778)$ & Wedge $(n=4517)$ & St Diff & SBRT $(n=1584)$ & Wedge $(n=1584)$ & St Diff \\
\hline Age, y & $74[68,80]$ & $69[63,76]$ & 48.17 & $73[67,79]$ & $73[67,79]$ & 1.17 \\
\hline Sex & & & 3.80 & & & 4.12 \\
\hline Male & $41.0 \%(729)$ & $39.1 \%(1768)$ & & $41.3 \%(654)$ & $39.3 \%(622)$ & \\
\hline Female & $59.0 \%(1049)$ & $60.9 \%(2749)$ & & $58.7 \%(930)$ & $60.7 \%(962)$ & \\
\hline Race & & & 0.25 & & & 0.87 \\
\hline White & $90.9 \%(1601)$ & $90.8 \%(4077)$ & & $90.9 \%(1440)$ & $90.7 \%(1436)$ & \\
\hline Nonwhite & $9.1 \%(160)$ & $9.2 \%(411)$ & & $9.1 \%(144)$ & $9.3 \%(148)$ & \\
\hline Insurance status & & & 30.90 & & & 0.18 \\
\hline Private & $14.8 \%(313)$ & $27.1 \%(1223)$ & & $15.1 \%(239)$ & $15.0 \%(238)$ & \\
\hline Nonprivate & $84.6 \%(1766)$ & $71.8 \%(3245)$ & & $84.9 \%(1345)$ & $85.0 \%(1346)$ & \\
\hline Charlson-Deyo Score & & & 17.91 & & & 0.72 \\
\hline 0 & $54.8 \%(975)$ & $42.0 \%(1899)$ & & $52.0 \%(824)$ & $51.5 \%(816)$ & \\
\hline 1 & $28.9 \%(513)$ & $40.1 \%(1813)$ & & $31.0 \%(491)$ & $31.4 \%$ (497) & \\
\hline $2+$ & $16.3 \%(290)$ & $17.8 \%(805)$ & & $17.0 \%(269)$ & $17.1 \%(271)$ & \\
\hline Facility type & & & 19.05 & & & 0.38 \\
\hline Nonacademic & $54.4 \%(967)$ & $63.7 \%(2878)$ & & $57.1 \%(905)$ & $56.9 \%(902)$ & \\
\hline Academic & $45.6 \%(811)$ & $36.3 \%(1639)$ & & $42.9 \%(679)$ & $43.1 \%(682)$ & \\
\hline Tumor location & & & 5.69 & & & 2.94 \\
\hline Upper lobe & $64.1 \%(1140)$ & $60.8 \%(2745)$ & & $63.6 \%(1007)$ & $62.1 \%(984)$ & \\
\hline Lower lobe & $28.2 \%(502)$ & $32.0 \%(1448)$ & & $28.8 \%(457)$ & $30.7 \%(30.7)$ & \\
\hline Middle lobe/other & $7.7 \%(136)$ & $7.2 \%(324)$ & & $7.6 \%(120)$ & $7.1 \%(113)$ & \\
\hline Histology & & & 21.74 & & & 1.09 \\
\hline Adenocarcinoma & $40.3 \%(716)$ & $44.4 \%(2006)$ & & $42.7 \%(676)$ & $43.1 \%(682)$ & \\
\hline Squamous cell & $29.8 \%(529)$ & $22.9 \%(1034)$ & & $29.9 \%(474)$ & $29.8 \%(472)$ & \\
\hline BAC & $4.0 \%(72)$ & $15.9 \%(720)$ & & $4.4 \%(70)$ & $4.8 \%(76)$ & \\
\hline Other & $25.9 \%(461)$ & $16.8 \%(757)$ & & $23.0 \%(364)$ & $22.3 \%(354)$ & \\
\hline Tumor size, cm & $1.6[1.3,1.8]$ & $1.5[1.1,1.7]$ & 40.62 & $1.5[1.3,1.8]$ & $1.5[1.3,1.9]$ & 6.38 \\
\hline Distance to hospital, miles & & & 8.86 & & & 1.52 \\
\hline$\leq 60$ & $87.8 \%(1561)$ & $90.6 \%(4093)$ & & $90.5 \%(1434)$ & $91.0 \%(1441)$ & \\
\hline$>60$ & $10.4 \%(185)$ & $7.9 \%(357)$ & & $9.5 \%(150)$ & $9.0 \%(143)$ & \\
\hline
\end{tabular}

Data are represented as percent (number) for categorical variables and median [Q1, Q3] for continuous variables unless otherwise specified. SBRT, Stereotactic body radiotherapy; St Diff, standardized difference; $B A C$, bronchioloalveolar carcinoma. 


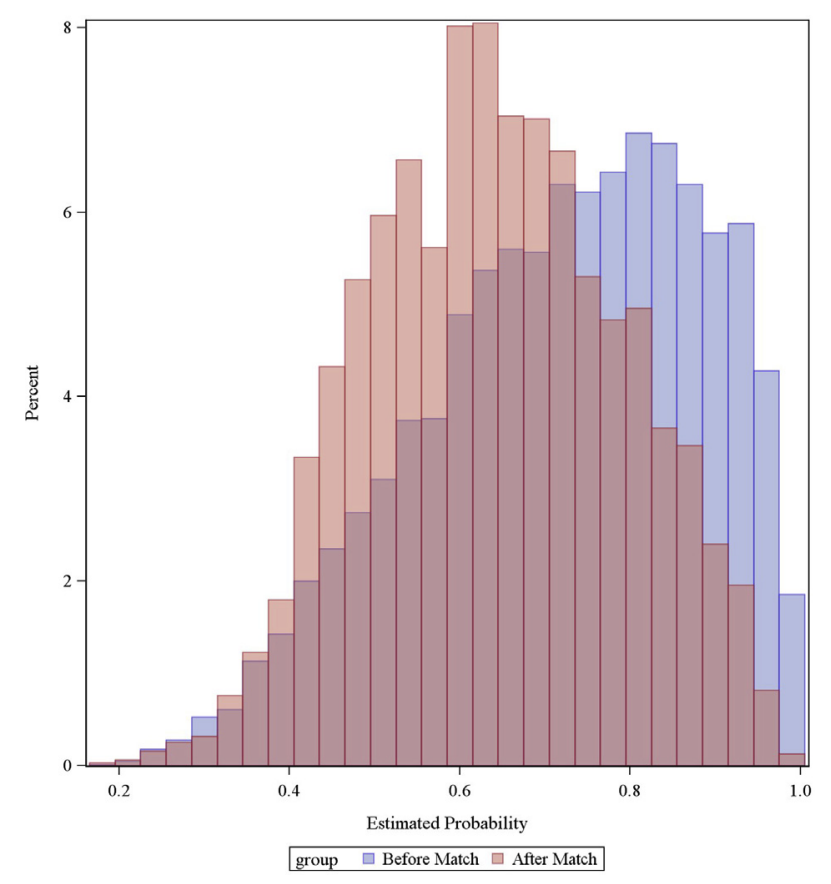

FIGURE 1. Overlap histogram for propensity score matching of the overall cohort.

have a higher Charlson-Deyo comorbidity score (Table 1). These patients were more likely to be treated at an academic comprehensive cancer program. The groups were similar in sex and race. The 5-year survival was decreased in the group receiving SBRT at 30.9\% (confidence interval [CI], 26.3\%-35.5\%) compared with 55.2\% (CI, 52.4\%$57.9 \%)$ in the wedge resection group $(P<.001)$ (Central Figure).

After propensity score matching, the 2 groups became similar with regard to their demographics and tumor characteristics (Figure 1). After matching 1584 patients from each group, the 5-year survival in the SBRT group remained decreased at $31.0 \%(\mathrm{CI}, 26.1 \%-36.0 \%)$ compared with a survival of $49.9 \%$ (CI, $45.1 \%-54.6 \%)$ in the wedge resection group $(P<.001)$ (Figure 2$)$.

\section{Patients Older Than 80 Years Subgroup Analysis}

To test whether SBRT compromised survival in the elderly, a subgroup analysis was performed in patients older than 80 years (Table 2). In the subgroup of 898 patients, 409 received SBRT and 489 patients underwent wedge resection. The wedge resection group had an improved 5-year survival of $40.1 \%$ (CI, 31.3\%-48.8\%) compared with $22.6 \%$ (CI, $13.8 \%-32.9 \%$ ) for the SBRT group $(P<.001)$. We similarly performed a propensity scorematched analysis with 319 patients from each group. In this cohort, a 5-year survival advantage still remained for the wedge resection group compared with the SBRT group respectively, $(P=.007)$ (Figure E2).

\section{Patients With a Charlson-Deyo Score of 2 or Greater Subgroup Analysis}

To determine the effect of SBRT in a cohort with multiple comorbidities, another subgroup analysis was performed in patients with a Charlson-Deyo comorbidity score of 2 or greater (Table 3). In this subgroup, 290 patients received SBRT and 805 patients underwent wedge resection. In this cohort, a 5-year survival advantage was seen in the wedge resection group $(P<.001)$, which remained after we adjusted for patient and tumor characteristics $(P=.020)$ (Figure E3).

\section{Center-Level Analysis}

Centers treating study patients were then compared by $\mathrm{O} / \mathrm{E}$ ratios for survival. Centers were stratified then divided into 4 quartiles based off the percentage of SBRT patients relative to their overall cohort of study patients. The centers that predominantly performed wedge resections for their study patients were in the first quartile, whereas centers that mainly performed SBRT for their patients were in the fourth quartile. The quartiles did not differ in their makeup of academic and nonacademic facilities (all $P>$.05). O/E mortality was compared at 1 month, 1 year, 2 years, and 3 years from disease diagnosis with the use of multivariable logistic regression models for each time point separately. These centers were then stratified based on their use of SBRT versus wedge resection. A total of 223 centers initially met inclusion criteria.

At the 1-month time point (Figure E4), a significant trend was observed $(P=.048)$ in which lower-quartile centers (predominantly wedge resection quartile) were less likely to have an $\mathrm{O} / \mathrm{E}$ ratio less than 1 (performed better than expected) for 30-day mortality (Table 4); however, this trend was not present at the 1-year time point (Figure E5). At the 2-year time point (Figure E6), however, a significant trend was observed $(P=.005)$ in which lower-quartile centers more often had an O/E ratio less than 1. Conversely, the highest quartile (predominately SBRT quartile) more often had an O/E ratio greater than 1 (performed worse than expected). The trend continued into the 3 -year time point and remained statistically significant $(P=.034)$ (Figure 3$)$.

\section{DISCUSSION}

This comparative analysis of wedge resection with SBRT in patients thought to be surgical candidates is significant and informative. Among patients with clinical-stage IA NSCLC, we found that SBRT was associated with a significant survival disadvantage compared with wedge resection. This survival disadvantage was notable in both the overall cohort as well as in the subgroups of older patients 


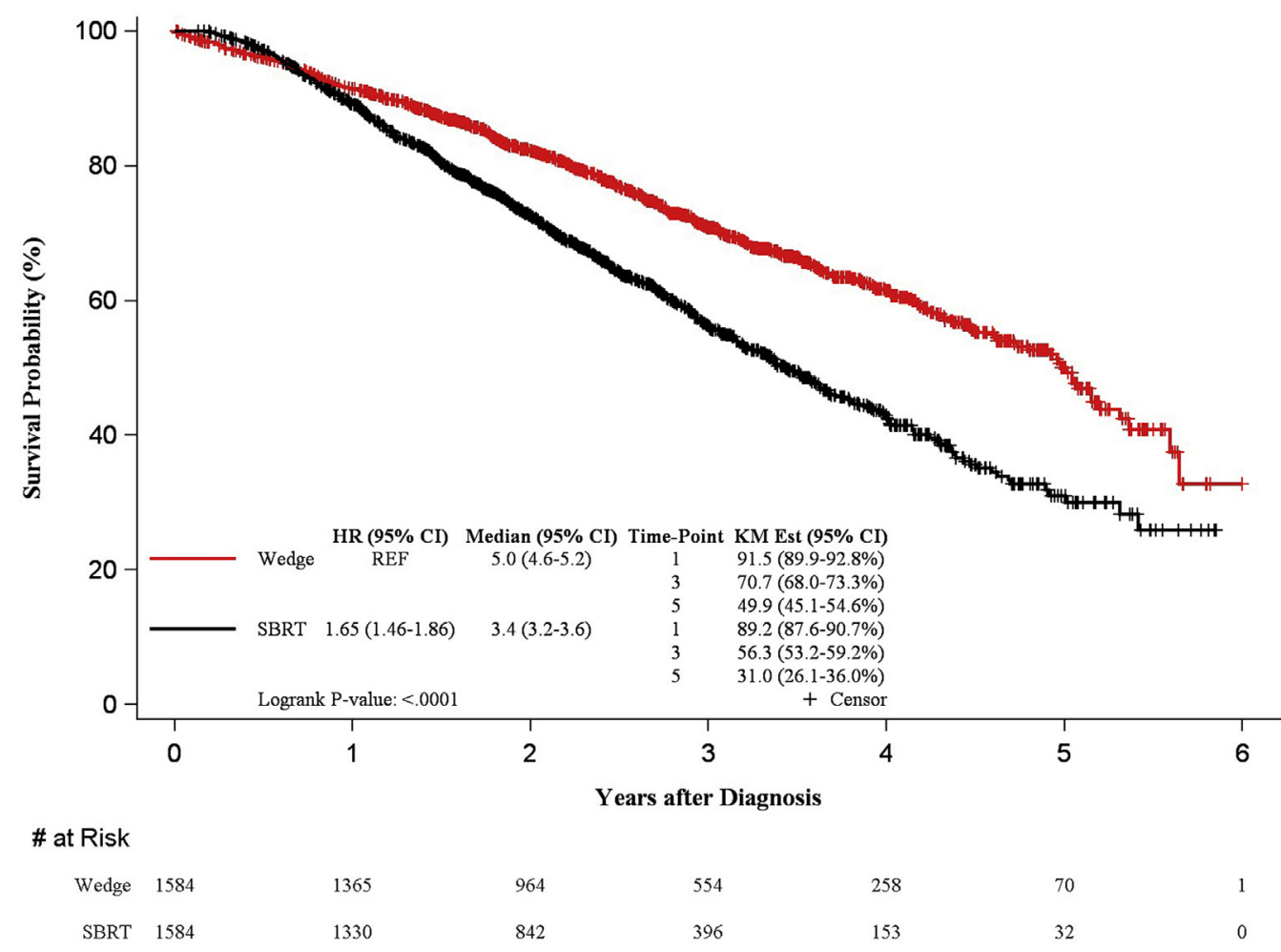

FIGURE 2. Kaplan-Meier-adjusted survival of patients with clinical-stage IA NSCLC. Overall survival of matched groups is shown. $H R$, Hazard ratio; $C I$, confidence interval; KM Est, Kaplan-Meier estimate; $R E F$, reference group; $S B R T$, stereotactic body radiotherapy.

and patients with comorbid disease. Finally, when analyzing the association between center use of SBRT and mortality, we found that SBRT use was associated with a higher center mortality than expected.

Although numerous phase 2 studies have demonstrated the efficacy of SBRT over external beam radiation in NSCLC patients deemed inoperable, ${ }^{25-29}$ its role in the management of operable patients is still being defined. The landmark study by Zimmermann and colleagues ${ }^{28}$ introduced SBRT into the field of thoracic oncology by demonstrating its efficacy over external beam radiation. Afterwards, the role of SBRT in replacement of surgery has been investigated actively. Initially, 2 phase 2 clinical trials opened in Japan and the United States investigating SBRT in operable patients with clinical-stage I NSCLC: the Japan Clinical Oncology Group (JCOG) 0403 and Radiation Therapy Oncology Group (RTOG) 0618, respectively. Recently published, JCOG 0403 reported a 3-year overall survival of $76.5 \%,{ }^{30}$ which is inconsistent with our observed unadjusted 3-year survival in our SBRT group.

A couple factors may account for the difference. The JCOG 0403 study required rigid criteria defining which patients were operable. Patients had to have an expected postoperative forced expiratory volume in 1 second $>800 \mathrm{~mL}$, a $\mathrm{PaO}_{2}>65$ torr, no severe cardiac morbidity, and no severe diabetes mellitus. Defining operability outside of a clinical trial setting is difficult because this definition may be different between surgeons. In addition, patients in the study who fulfilled the operable criteria could afterwards be determined as inoperable by the study committee, which accounted for approximately one third of patients who met initial operable criteria being then being excluded after committee screening. Another possible factor that could explain the difference in survival is the fact that our SBRT group may be a sicker cohort of patients. The results of RTOG 0618 remain unpublished.

Previous retrospective analyses also have attempted to delineate the feasibility of SBRT in operable patients mainly through propensity score matching. ${ }^{13,15-17,31}$ Shirvani and colleagues ${ }^{15}$ reported outcomes from the Surveillance, Epidemiology, and End Results database of 9093 patients undergoing either lobectomy, sublobar resection, or SBRT, showing an improved survival with lobectomy when compared with sublobar resection and SBRT. However a limitation of this analysis and the Surveillance, Epidemiology, and End Results database is that it only captures "best staging available," meaning if the initial therapy was surgery, the staging would be pathologic staging, and if the initial staging was radiation, the staging would be clinical staging. Without the delineation between clinical and pathologic staging, this limits the generalizability of the results. 


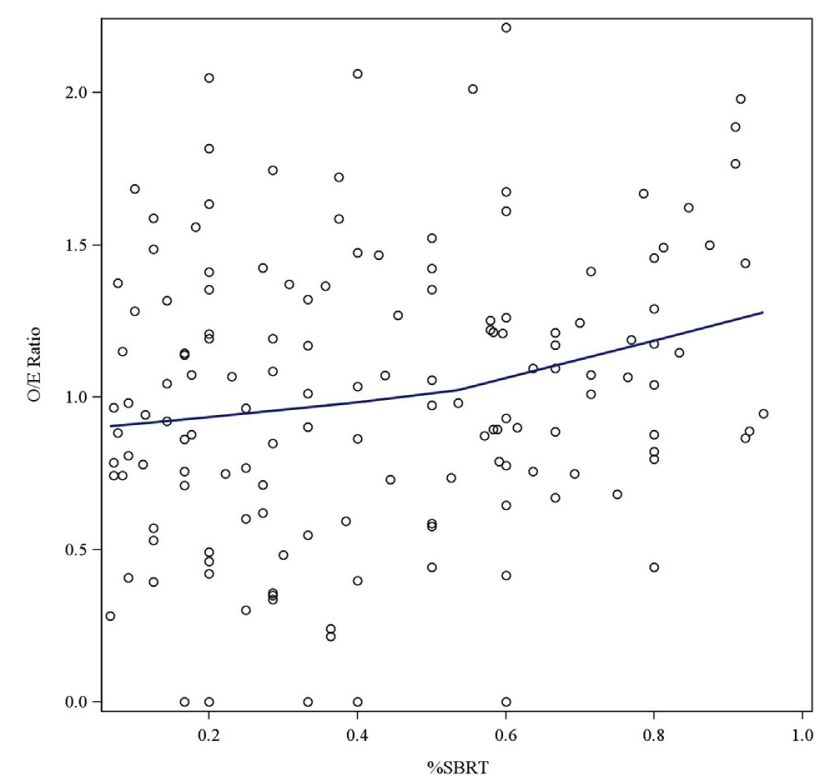

FIGURE 3. Center-level comparison of SBRT to wedge resection. Scatter plot of centers stratified by their center ratio of SBRT/wedge. First-quartile centers predominately used wedge resection, whereas fourth-quartile centers predominately used SBRT. Centers with either all SBRT patients, all wedge resection patients, or with less than 5 patients were excluded. Quartiles were compared using a ratio of observed mortality to expected mortality with an $\mathrm{O} / \mathrm{E} \leq 1$ indicating similar or better performance than expected and an $\mathrm{O} / \mathrm{E}>1$ indicating worse performance than expected. Depicted is center 3-year mortality O/E ratios. $O / E$, Observed to expected; $\% S B R T$, percent stereotactic body radiotherapy use.

Two other retrospective studies have attempted to analyze the effectiveness of SBRT by excluding inoperable patients. Lagerwaard and colleagues ${ }^{12}$ published their single institutional experience, reporting an $84.7 \%$ 3-year overall survival in their "potentially operable" SBRT cohort with clinical-stage I NSCLC. Another study used multi-institutional data from Japan to retrospectively analyze SBRT in potentially operable clinical-stage I NSCLC patients by excluding patients deemed inoperable $^{14}$; they reported a 5-year overall survival of $69.5 \%$. Again, stricter criteria defining operable patients providing a healthier subset of operable SBRT patients could possibly explain the difference between the results of these 2 studies versus ours. In addition, this difference may possibly be attributable to the efficacy of SBRT in the clinical research setting and the effectiveness of SBRT in practicality.

This study contributes significant information to the current literature regarding surgery versus SBRT. In another analysis, Puri and colleagues,${ }^{17}$ also using the NCDB, reported outcomes of 117,618 patients undergoing either surgical resection or SBRT. They showed a survival advantage for surgical resection. They also performed a subgroup analysis of patients who underwent sublobar resection compared with SBRT that also showed a survival advantage for resection.

Several analyses in our study merit consideration. We limited our analysis to small tumors $(\leq 2 \mathrm{~cm})^{1}$ to allow for a comparison in a more homogenous population considered to be the "best" candidates for SBRT and thus minimizing bias. Also, by focusing specifically on wedge resection, we allow for the comparison of one surgical procedure with its known limitations to SBRT, again decreasing bias. In doing so, we found a higher potentially more accurate median survival in our SBRT group of 40.8 months compared with 33.1 months reported by Puri and colleagues. ${ }^{17}$

Finally, our center-level sensitivity analysis strengthens our overall analysis and attempts to increase external validity by showing consistency between the results of our primary and sensitivity analysis. Our centerlevel analysis also shows a dose-response relationship between the use of SBRT and center mortality. All these factors enhance our ability to make a causal inference between SBRT and increased mortality in patients with early-stage NSCLC.

These issues related to observational research highlight the need for a prospective randomized clinical trial, but unfortunately this has not been achievable. The 3 initial randomized clinical trials comparing SBRT with surgery (Randomized Study to Compare CyberKnife to Surgical Resection In Stage I Non-Small Cell Lung Cancer [STARS], ${ }^{10}$ Trial of Either Surgery or Stereotactic Radiotherapy for Early Stage (IA) Lung Cancer [ROSEL], ${ }^{11}$ and American College of Surgeons Oncology Group Z4099/RTOG 1021 ${ }^{9}$ ) have all been terminated secondary to poor patient accrual likely related to the patient difficulty of randomizing between dramatically different treatment modalities. However, Chang and colleagues ${ }^{32}$ published the combined results of 58 patients with stage I NSCLC in the STARS and ROSEL trials, reporting a survival advantage with SBRT compared with lobectomy. Even these result, however, are difficult to interpret, given the different inclusion criteria of both trials. In addition, the overall survival was significantly different in the STARS trial alone $(P=.0067)$ but not in the ROSEL trial $(P=.78)$. New randomized trials, including A Randomized Phase III Study of Sublobar Resection (SR) versus Stereotactic Ablative Radiotherapy (SAbR) in High Risk Patients with Stage I Non-Small Cell Lung Cancer (NSCLC) (STABLe-mates; CT01622621, formerly American College of Surgeons Oncology Group Z4099), SABRTooth (ISRCTN13029788), ${ }^{33}$ and Vosaroxin or Placebo in Combination With Cytarabine in Patients With First Relapsed or Refractory Acute Myeloid Leukemia (VALOR; CSP 2005), are now ongoing, but their ability to accrue patients remain to be determined, 
TABLE 2. Age greater than 80 y subgroup analysis: Unmatched and propensity score-matched patient characteristics

\begin{tabular}{|c|c|c|c|c|c|c|}
\hline & \multicolumn{3}{|c|}{ Unmatched } & \multicolumn{3}{|c|}{ Matched } \\
\hline & SBRT $(n=409)$ & Wedge $(n=489)$ & St diff & SBRT $(n=319)$ & Wedge $(n=319)$ & St diff \\
\hline Age, y & $83[82,86]$ & $83[82,85]$ & 11.46 & $83[82,85]$ & $83[82,85]$ & 2.01 \\
\hline Sex & & & 12.54 & & & 1.92 \\
\hline Male & $37.4 \%(153)$ & $43.6 \%(213)$ & & $39.5 \%(126)$ & $40.4 \%$ (129) & \\
\hline Female & $62.6 \%(256)$ & $56.4 \%(276)$ & & $60.5 \%(193)$ & $59.6 \%(190)$ & \\
\hline Race & & & 4.78 & & & 3.67 \\
\hline White & $92.4 \%(377)$ & $93.6 \%(455)$ & & $92.5 \%(295)$ & $93.4 \%$ (298) & \\
\hline Nonwhite & $7.6 \%(31)$ & $6.4 \%(31)$ & & $7.5 \%(24)$ & $6.6 \%(21)$ & \\
\hline Insurance status & & & 4.93 & & & 3.59 \\
\hline Private & $7.9 \%(32)$ & $6.6 \%(32)$ & & $7.8 \%(25)$ & $6.9 \%(22)$ & \\
\hline Nonprivate & $92.1 \%(375)$ & $93.4 \%(454)$ & & $92.2 \%(294)$ & $93.1 \%$ (297) & \\
\hline Charlson-Deyo Score & & & 19.52 & & & 3.13 \\
\hline 0 & $59.4 \%(243)$ & $46.2 \%(226)$ & & $53.0 \%(169)$ & $53.0 \%(169)$ & \\
\hline 1 & $29.3 \%(120)$ & $37.6 \%(184)$ & & $33.9 \%(108)$ & $32.0 \%(102)$ & \\
\hline $2+$ & $11.2 \%(46)$ & $16.2 \%(79)$ & & $13.2 \%(42)$ & $15.0 \%(48)$ & \\
\hline Facility type & & & 19.54 & & & 5.21 \\
\hline Nonacademic & $57.2 \%(234)$ & $66.7 \%(326)$ & & $64.9 \%(207)$ & $62.4 \%$ (199) & \\
\hline Academic & $42.8 \%(175)$ & $33.3 \%(163)$ & & $35.1 \%(112)$ & $37.6 \%(120)$ & \\
\hline Tumor location & & & 9.67 & & & 5.41 \\
\hline Upper lobe & $61.4 \%(251)$ & $57.3 \%(280)$ & & $61.1 \%(195)$ & $61.4 \%(196)$ & \\
\hline Lower lobe & $30.1 \%(123)$ & $36.2 \%(177)$ & & $32.6 \%(104)$ & $29.8 \%(95)$ & \\
\hline Middle lobe/other & $8.6 \%(35)$ & $6.5 \%(32)$ & & $6.3 \%(20)$ & $8.8 \%(28)$ & \\
\hline Histology & & & 17.14 & & & 1.29 \\
\hline Adenocarcinoma & $41.1 \%(168)$ & $41.3 \%(202)$ & & $45.1 \%(144)$ & $44.2 \%(141)$ & \\
\hline Squamous cell & $28.1 \%(115)$ & $28.2 \%(138)$ & & $31.0 \%(99)$ & $31.0 \%(99)$ & \\
\hline $\mathrm{BAC}$ & $5.4 \%(22)$ & $17.0 \%(83)$ & & $6.9 \%(22)$ & $7.5 \%(24)$ & \\
\hline Other & $25.4 \%(104)$ & $13.5 \%(66)$ & & $16.9 \%(54)$ & $17.2 \%(5)$ & \\
\hline Tumor size, $\mathrm{cm}$ & $1.7[1.4,1.9]$ & $1.5[1.2,1.8]$ & 31.96 & $1.5[1.3,1.8]$ & $1.5[1.3,1.8]$ & 0.44 \\
\hline Distance to hospital, miles & & & 5.59 & & & 3.46 \\
\hline$\leq 60$ & $92.6 \%(375)$ & $91.1 \%(438)$ & & $92.5 \%(295)$ & $91.5 \%(292)$ & \\
\hline$>60$ & $7.4 \%(30)$ & $8.9 \%(43)$ & & $7.5 \%(24)$ & $8.5 \%(27)$ & \\
\hline
\end{tabular}

Data are represented as percent (number) for categorical variables and median [Q1, Q3] for continuous variables unless otherwise specified. SBRT, Stereotactic body radiotherapy; St Diff, standardized difference; $B A C$, bronchioloalveolar carcinoma.

and it is likely to be several years before results are reported.

Despite the strong statistical methodology employed in our overall analysis, the overall survival advantage seen with wedge resection when compared with SBRT could possibly be secondary to selection bias. Recognizing the challenge, we used both propensity score matching on a patient level and $\mathrm{O} / \mathrm{E}$ ratios for a center-level comparison to come to the same conclusion. Although this does not completely negate the selection bias, it strengthens the potential validity of our results.

In addition, not all wedge resection is limited to treatment of the immediate lung parenchyma, as many surgeons will perform concomitant lymphadenectomy. The additional value of lymph node sampling will, at a minimum, facilitate more accurate staging and determine adjuvant therapy. In our SBRT group, pathologically node-positive but clinically undetected cases were included as early-stage cancers and likely experienced worse survival, whereas the patients upstaged at surgery may have been offered additional therapy.

Our study has other limitations as well. First, as a limitation of our dataset, disease-free survival, diseasespecific survival, and locoregional recurrence could not be captured. Second, the quality of SBRT has evolved and improved over the years of the study, possibly making the SBRT overall survival less comparable with present-day SBRT. Furthermore, not all patients who underwent SBRT may have had tumors that were amenable to wedge resection. In fact, many may have had central tumors that required lobectomy or even pneumonectomy, so wedge resection was not even an option (and that is why they did not get a wedge resection). Third, the NCDB does not capture pulmonary function testing, which introduces another element for potential bias. Finally, our analysis was retrospective in nature and thus subjected to incompleteness of data and coding errors. Nonetheless, our study is the largest cohort study 
TABLE 3. Charlson-Deyo score 2 or greater subgroup analysis: Unadjusted and propensity-matched patient characteristics

\begin{tabular}{|c|c|c|c|c|c|c|}
\hline & \multicolumn{3}{|c|}{ Unmatched } & \multicolumn{3}{|c|}{ Matched } \\
\hline & SBRT $(n=290)$ & Wedge $(n=805)$ & St Diff & SBRT $(n=267)$ & Wedge $(n=267)$ & St Diff \\
\hline Age, y & $72[67,78]$ & $70[65,76]$ & 26.32 & $72[67,78]$ & $72[67,77]$ & 3.57 \\
\hline Sex & & & 3.22 & & & 3.76 \\
\hline Male & $44.5 \%(129)$ & $46.1 \%(371)$ & & $45.3 \%(121)$ & $43.4 \%(116)$ & \\
\hline Female & $55.5 \%(161)$ & $53.9 \%(434)$ & & $54.7 \%(146)$ & $56.6 \%(151)$ & \\
\hline Race & & & 9.60 & & & 2.33 \\
\hline White & $87.8 \%(252)$ & $90.8 \%(728)$ & & $88.0 \%(235)$ & $88.8 \%(237)$ & \\
\hline Nonwhite & $12.2 \%$ & $9.2 \%(74)$ & & $12.0 \%(32)$ & $11.2 \%(30)$ & \\
\hline Insurance status & & & 17.29 & & & 4.43 \\
\hline Private & $13.1 \%(38)$ & $19.5 \%(156)$ & & $12.4 \%(33)$ & $13.9 \%(37)$ & \\
\hline Nonprivate & $86.9 \%(251)$ & $80.5 \%(643)$ & & $87.6 \%(234)$ & $86.1 \%(230)$ & \\
\hline Facility type & & & 22.02 & & & 2.26 \\
\hline Nonacademic & $55.5 \%(161)$ & $66.2 \%(533)$ & & $57.3 \%(153)$ & $56.2 \%(150)$ & \\
\hline Academic & $44.5 \%(129)$ & $33.8 \%(272)$ & & $42.7 \%(114)$ & $43.8 \%(117)$ & \\
\hline Tumor location & & & 1.57 & & & 9.00 \\
\hline Upper lobe & $64.1 \%(186)$ & $64.7 \%(521)$ & & $64.4 \%(172)$ & $59.2 \%(158)$ & \\
\hline Lower lobe & $30.0 \%(87)$ & $29.1 \%(234)$ & & $30.3 \%(81)$ & $33.0 \%(88)$ & \\
\hline Middle lobe/other & $5.9 \%(17)$ & $6.2 \%(50)$ & & $5.2 \%(14)$ & $7.9 \%(21)$ & \\
\hline Histology & & & 14.84 & & & 6.09 \\
\hline Adenocarcinoma & $41.7 \%(121)$ & $43.7 \%(352)$ & & $44.2 \%(118)$ & $41.2 \%(110)$ & \\
\hline Squamous cell & $30.7 \%(89)$ & $29.7 \%(239)$ & & $30.7 \%(82)$ & $28.8 \%(77)$ & \\
\hline BAC & $3.8 \%(11)$ & $11.8 \%(95)$ & & $4.1 \%(11)$ & $5.2 \%(14)$ & \\
\hline Other & $23.8 \%(69)$ & $14.8 \%(119)$ & & $21.0 \%(56)$ & $24.7 \%(66)$ & \\
\hline Tumor size, $\mathrm{cm}$ & $1.6[1.3,1.8]$ & $1.5[1.2,1.8]$ & 25.78 & $1.6[1.3,1.8]$ & $1.6[1.3,1.8]$ & 4.50 \\
\hline Distance to hospital, miles & & & 13.76 & & & 6.06 \\
\hline$\leq 60$ & $88.1 \%(251)$ & $92.2 \%(730)$ & & $90.3 \%(241)$ & $88.4 \%(236)$ & \\
\hline$>60$ & $11.9 \%(34)$ & $7.8 \%(62)$ & & $9.7 \%(26)$ & $11.6 \%(31)$ & \\
\hline
\end{tabular}

Data are represented as percent (number) for categorical variables and median [Q1, Q3] for continuous variables unless otherwise specified. SBRT, Stereotactic body radiotherapy; St Diff, standardized difference; $B A C$, bronchioloalveolar carcinoma.

to specifically compare wedge resection with SBRT in clinical-stage IA NSCLC (Video 1).

\section{CONCLUSIONS}

In conclusion, this analysis using the NCDB demonstrates that SBRT is associated with decreased survival compared with wedge resection for patients with clinicalstage IA NSCLC. Our results highlight the need for multidisciplinary involvement in the evaluation of patients with early-stage lung cancer and that operable patients should be counseled regarding the potential compromise in survival associated with SBRT even for tumors $\leq 2 \mathrm{~cm}$ in

TABLE 4. Center-level analysis of mortality and use of SBRT versus wedge resection by quartiles

\begin{tabular}{|c|c|c|c|c|c|c|}
\hline & 0-25th & 26-50th & 51-75th & 76-100th & Total & $P$ value \\
\hline 30-d O/E ratio & & & & & & .176 \\
\hline$\leq 1$ & $53(91.4 \%)$ & $57(98.3 \%)$ & $57(96.6 \%)$ & $56(98.2 \%)$ & $223(96.1 \%)$ & \\
\hline$>1$ & $5(8.6 \%)$ & $1(1.7 \%)$ & $2(3.4 \%)$ & $1(1.8 \%)$ & $9(3.9 \%)$ & \\
\hline 1-y O/E ratio & & & & & & .742 \\
\hline$\leq 1$ & $32(58.2 \%)$ & $35(63.6 \%)$ & $30(54.5 \%)$ & $30(54.5 \%)$ & $127(57.7 \%)$ & \\
\hline$>1$ & $23(41.8 \%)$ & $20(36.4 \%)$ & $25(45.5 \%)$ & $25(45.5 \%)$ & $93(42.3 \%)$ & \\
\hline 2-y O/E ratio & & & & & & .067 \\
\hline$\leq 1$ & $29(63.0 \%)$ & $29(60.4 \%)$ & $20(44.4 \%)$ & $19(40.4 \%)$ & $97(52.2 \%)$ & \\
\hline$>1$ & $17(37.0 \%)$ & $19(39.6 \%)$ & $25(55.6 \%)$ & $28(59.6 \%)$ & $89(47.8 \%)$ & \\
\hline 3-y O/E ratio & & & & & & .208 \\
\hline$\leq 1$ & $24(55.8 \%)$ & $18(60.0 \%)$ & $19(50.0 \%)$ & $13(36.1 \%)$ & $74(50.3 \%)$ & \\
\hline$>1$ & $19(44.2 \%)$ & $12(40.0 \%)$ & $19(50.0 \%)$ & $23(63.9 \%)$ & $73(49.7 \%)$ & \\
\hline
\end{tabular}

First-quartile centers predominately used wedge resection, whereas fourth-quartile centers predominately used SBRT. Centers with either all SBRT patients, all wedge resection patients, or with less than 5 patients were excluded. Quartiles were compared with a ratio of observed mortality to expected mortality with an O/E $<1$ indicating better performance than expected and an $\mathrm{O} / \mathrm{E}>1$ indicating worse performance than expected. Mortality was calculated at 1 month, 1 year, 2 years, and 3 years. $O / E$, Observed to expected. 


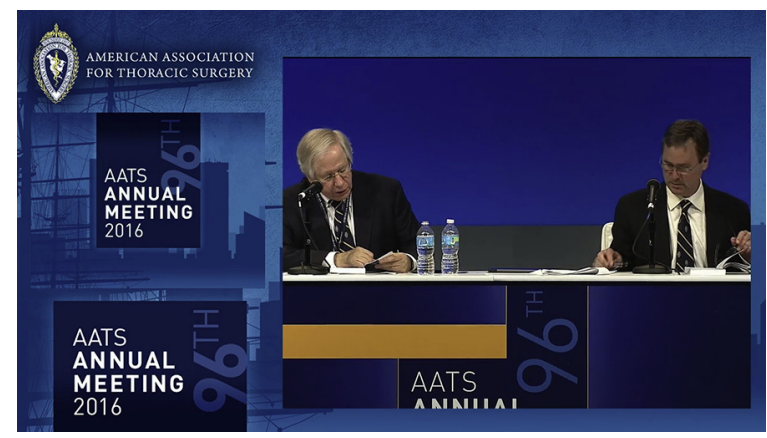

VIDEO 1. Oral presentation of the paper from the AATS 2016 Annual Meeting. Video available at: http://www.jtcvsonline.org/article/S00225223(17)30639-6/addons.

size. Finally, prospective randomized studies to delineate the method of management for patients with early-stage NSCLC are needed. Until these trials are able to be completed, SBRT should be used very cautiously for patients who could potentially tolerate surgery so that survival of these patients is optimized.

\section{Webcast}

You can watch a Webcast of this AATS meeting presentation by going to: http://webcast.aats.org/2016/Video/ Monday/05-16-16_Hall_E_0810_Yerokun-800.mp4.

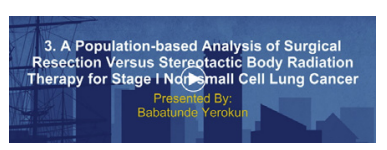

\section{Conflict of Interest Statement}

Thomas A. D'Amico serves as a consultant for Scanlan. All other authors have nothing to disclose with regard to commercial support.

\section{References}

1. Ettinger DS, Wood DE, Akerley W, Bazhenova LA, Borghaei H, Camidge DR, et al. Non-Small Cell Lung Cancer, Version 6.2015. J Natl Compr Cancer Netw. 2015;13:515-24.

2. Altorki NK, Yip R, Hanaoka T, Bauer T, Aye R, Kohman L, et al. Sublobar resection is equivalent to lobectomy for clinical stage 1A lung cancer in solid nodules. J Thorac Cardiovasc Surg. 2014;147:754-62; discussion 762-4.

3. Koike T, Yamato Y, Yoshiya K, Shimoyama T, Suzuki R. Intentional limited pulmonary resection for peripheral T1 N0 M0 small-sized lung cancer. J Thorac Cardiovasc Surg. 2003;125:924-8.

4. Howington JA, Blum MG, Chang AC, Balekian AA, Murthy SC. Treatment of stage I and II non-small cell lung cancer: diagnosis and management of lung cancer, 3rd ed: American College of Chest Physicians evidence-based clinical practice guidelines. Chest. 2013;143:e278S-313S.

5. Pan H, Rose BS, Simpson DR, Mell LK, Mundt AJ, Lawson JD. Clinical practice patterns of lung stereotactic body radiation therapy in the United States: a secondary analysis. Am J Clin Oncol. 2013;36:269-72.

6. Dunlap NE, Larner JM, Read PW, Kozower BD, Lau CL, Sheng K, et al. Size matters: a comparison of $\mathrm{T} 1$ and $\mathrm{T} 2$ peripheral non-small-cell lung cancers treated with stereotactic body radiation therapy (SBRT). J Thorac Cardiovasc Surg. 2010;140:583-9.
7. Reyngold M, Wu AJ, McLane A, Zhang Z, Hsu M, Stein NF, et al. Toxicity and outcomes of thoracic re-irradiation using stereotactic body radiation therapy (SBRT). Radiat Oncol. 2013;8:1.

8. Ezer N, Veluswamy RR, Mhango G, Rosenzweig KE, Powell CA, Wisnivesky JP. Outcomes after stereotactic body radiotherapy versus limited resection in older patients with early-stage lung cancer. J Thorac Oncol. 2015;10:1201-6.

9. Alliance for Clinical Trials in Oncology. Surgery With Or Without Internal Radiation Therapy Compared With Stereotactic Body Radiation Therapy in Treating Patients With High-Risk Stage I Non-Small Cell Lung Cancer. In ClinicalTrials.gov [Internet]. Bethesda, MD: National Library of Medicine (US); 2000. NLM Identifier: NCT01336894. Available at: https://clinicaltrials. gov/ct2/show/NCT01336894. Accessed September 30, 2016.

10. M.D. Anderson Cancer Center. Randomized Study to Compare CyberKnife to Surgical Resection in Stage I Non-small Cell Lung Cancer (STARS). In: ClinicalTrials.gov [Internet]. Bethesda (MD): National Library of Medicine (US); 2000. NLM Identifier: NCT00840749. Available at: https://clinicaltrials.gov/ ct2/show/NCT00840749. Accessed September 30, 2016.

11. VU University Medical Center. Trial of Either Surgery or Stereotactic Radiotherapy for Early Stage (IA) Lung Cancer (ROSEL). In: ClinicalTrials.gov [Internet]. Bethesda (MD): National Library of Medicine (US); 2000. NLM Identifier: NCT00687986. Available at: https://clinicaltrials.gov/ct2/show/ NCT00687986. Accessed September 30, 2016.

12. Lagerwaard FJ, Verstegen NE, Haasbeek CJ, Slotman BJ, Paul MA, Smit EF, et al. Outcomes of stereotactic ablative radiotherapy in patients with potentially operable stage I non-small cell lung cancer. Int J Radiat Oncol Biol Phys. 2012; $83: 348-53$.

13. Mokhles S, Verstegen N, Maat AP, Birim O, Bogers AJ, Mokhles MM, et al. Comparison of clinical outcome of stage I non-small cell lung cancer treated surgically or with stereotactic radiotherapy: results from propensity score analysis. Lung Cancer. 2015;87:283-9.

14. Onishi H, Shirato H, Nagata Y, Hiraoka M, Fujino M, Gomi K, et al. Stereotactic body radiotherapy (SBRT) for operable stage I non-small-cell lung cancer: can SBRT be comparable to surgery? Int J Radiat Oncol Biol Phys. 2011;81:1352-8.

15. Shirvani SM, Jiang J, Chang JY, Welsh J, Likhacheva A, Buchholz TA, et al. Lobectomy, sublobar resection, and stereotactic ablative radiotherapy for earlystage non-small cell lung cancers in the elderly. JAMA Surg. 2014;149:1244-53.

16. Verstegen NE, Oosterhuis JW, Palma DA, Rodrigues G, Lagerwaard FJ, van der Elst A, et al. Stage I-II non-small-cell lung cancer treated using either stereotactic ablative radiotherapy (SABR) or lobectomy by video-assisted thoracoscopic surgery (VATS): outcomes of a propensity score-matched analysis. Ann Oncol. 2013;24:1543-8.

17. Puri V, Crabtree TD, Bell JM, Broderick SR, Morgensztern D, Colditz GA, et al Treatment outcomes in stage I lung cancer: a comparison of surgery and stereotactic body radiation therapy. J Thorac Oncol. 2015;10:1776-84.

18. Rosen JE, Salazar MC, Wang Z, Yu JB, Decker RH, Kim AW, et al. Lobectomy versus stereotactic body radiotherapy in healthy patients with stage I lung cancer. J Thorac Cardiovasc Surg. 2016;152:44-54.e9.

19. Bilimoria KY, Stewart AK, Winchester DP, Ko CY. The National Cancer Data Base: a powerful initiative to improve cancer care in the United States. Ann Surg Oncol. 2008;15:683-90.

20. Ettinger DS, Akerley W, Bepler G, Blum MG, Chang A, Cheney RT, et al. Nonsmall cell lung cancer. J Natl Compr Cancer Netw. 2010;8:740-801.

21. Collett D. Modelling Survival Data in Medical Research. Boca Raton, FL: CRC Press; 2015.

22. Van Belle G, Fisher LD, Heagerty PJ, Lumley T. Biostatistics: a Methodology for the Health Sciences. New York: John Wiley \& Sons; 2004.

23. Parsons LS. Performing a 1: $\mathrm{N}$ case-control match on propensity score Presented at: Proceedings of the 29th Annual SAS Users Group International Conference; May 9, 2004; Montréal, Canada.

24. Russell MC, You YN, Hu C-Y, Cormier JN, Feig BW, Skibber JM, et al. A novel risk-adjusted nomogram for rectal cancer surgery outcomes. JAMA Surg. 2013; 148:769-77.

25. Fakiris AJ, McGarry RC, Yiannoutsos CT, Papiez L, Williams M Henderson MA, et al. Stereotactic body radiation therapy for early-stage nonsmall-cell lung carcinoma: four-year results of a prospective phase II study. Int J Radiat Oncol Biol Phys. 2009;75:677-82.

26. Nagata Y, Takayama K, Matsuo Y, Norihisa Y, Mizowaki T, Sakamoto T, et al. Clinical outcomes of a phase I/II study of 48 Gy of stereotactic body radiotherapy in 4 fractions for primary lung cancer using a stereotactic body frame. Int J Radiat Oncol Biol Phys. 2005;63:1427-31. 
27. Ricardi U, Filippi AR, Guarneri A, Giglioli FR, Ciammella P, Franco P, et al. Stereotactic body radiation therapy for early stage non-small cell lung cancer: results of a prospective trial. Lung Cancer. 2010;68:72-7.

28. Timmerman R, Paulus R, Galvin J, Michalski J, Straube W, Bradley J, et al. Stereotactic body radiation therapy for inoperable early stage lung cancer. JAMA 2010;303:1070-6.

29. Zimmermann FB, Geinitz H, Schill S, Thamm R, Nieder C, Schratzenstaller U, et al. Stereotactic hypofractionated radiotherapy in stage I (T1-2 N0 M0) non-small-cell lung cancer (NSCLC). Acta Oncol. 2006;45:796-801.

30. Nagata Y, Hiraoka M, Shibata T, Onishi H, Kokubo M, Karasawa K, et al. Prospective Trial of Stereotactic Body Radiation Therapy for Both Operable and Inoperable T1N0M0 Non-Small Cell Lung Cancer: Japan Clinical Oncology Group Study JCOG0403. Int J Radiat Oncol Biol Phys. 2015; 93:989-96.

31. Crabtree TD, Denlinger CE, Meyers BF, El Naqa I, Zoole J, Krupnick AS, et al. Stereotactic body radiation therapy versus surgical resection for stage I non-small cell lung cancer. The J Thorac Cardiovasc Surg. 2010;140: 377-86.

32. Chang JY, Senan S, Paul MA, Mehran RJ, Louie AV, Balter P, et al. Stereotactic ablative radiotherapy versus lobectomy for operable stage I non-smallcell lung cancer: a pooled analysis of two randomised trials. Lancet Oncol. 2015; 16:630-7.

33. Snee MP, McParland L, Collinson F, Lowe CM, Striha A, Baldwin DR, et al. The SABRTooth feasibility trial protocol: a study to determine the feasibility and acceptability of conducting a phase III randomised controlled trial comparing stereotactic ablative radiotherapy (SABR) with surgery in patients with peripheral stage I non-small cell lung cancer (NSCLC) considered to be at higher risk of complications from surgical resection. Pilot Feasibility Stud. 2016;2:5. eCollection 2016.

Key Words: sublobar resection, wedge resection, stereotactic body radiotherapy, NSCLC, lung cancer, overall survival

\section{Discussion}

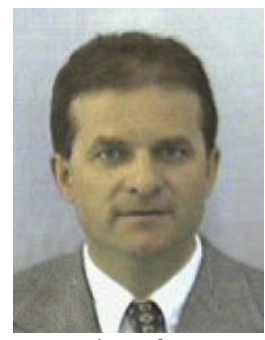

Dr W. Weder (Zurich, Switzerland). Dear Chairmen, colleagues, ladies, and gentlemen. I want to thank the Society for inviting me to discuss this very important contribution from Dr Yerokun and colleagues from Duke University.

The comparison of SBRT and wedge resection for stage IA lung cancer is of great interest, and this paper will largely contribute to the current debate. The study, based on the National Cancer Data Base from 2003 to 2011, demonstrates that wedge resection was associated with a better survival for patients with stage IA lung cancer compared with those treated by SBRT. The only cohort for which SBRT was not associated with a worse survival were patients older than 80 years and a Charlson-Deyo comorbidity score of more than 2 . In contrast to many studies in the literature, which use 3-year survival only, you report on 5-year and longer survival, which is important for assessing survival in early-stage lung cancer.

My questions. From an oncological standpoint, a 5-year survival of $32 \%$ for patients with stage IA treated by SBRT is unexpectedly poor and the difference to the $52 \%$ after wedge resection is unexpectedly large. What do you think has contributed to this result?

Dr Yerokun. In terms of the difference in the survival advantage associated with wedge resection compared with SBRT, there are a couple of reasons that the difference could be so dramatic. Number one, this study describes a real-world practice setting as opposed to clinical trials, which are the main source of literature for SBRT. Number two, our patients could be sicker in different ways not captured by the NCDB. The NCDB does not capture pulmonary function tests; it doesn't capture comorbidities on a granular level. However, the dataset does use the Charlson-Deyo score, which is a well-validated comorbidity score. And, third, it could be selection bias. Selection bias is inherent to any retrospective cohort analysis. However, despite that, our propensity score-matched analysis and our center-level sensitively analysis attempted to decrease the selection bias. Although not perfect, we believe this to be a rigorous attempt to account for this.

The main argument in any retrospective cohort analysis comparing any surgical intervention with a nonsurgical intervention is that the patients are different, inherently in some way not captured. By analyzing this on a center level, we not only adjusted on the patient level with logistic regression modeling, we also were able to remove centers that solely focused on one approach, hoping that this would make our groups more homogeneous. This in essence reduces the selection bias even more so than just normal propensity score matching.

As we all know, randomized controlled trial data are the best source of literature to determine causation, but in the absence of a randomized control trial, we have to rely on retrospective data.

Dr Weder. Thank you. How were the surgical procedures done, by video-assisted thoracoscopic surgery (VATS) or thoracotomy, and what was the 30-day mortality?

Dr Yerokun. In terms of VATS versus open, $40 \%$ were VATS, either thoracoscopic or robotic, and $60 \%$ were open, and the 30-day mortality in the SBRT group was 0 and in the wedge group was less than $1 \%$.

Dr Weder. Which radiotherapy dose was used for SBRT, and was tissue diagnosis available for all patients treated by radiotherapy?

Dr Yerokun. The mean radiation dose for the SBRT group was $52 \mathrm{~Gy}$, which is consistent with the latest phase 2 trial that was published, JCOG0403; their standard dose was $48 \mathrm{~Gy}$. In terms of a diagnosis, the NCDB requires all things documented to be histologically confirmed.

Dr Weder. Preoperative chemotherapy was not an exclusion criterion, despite it not being indicated in stage IA lung cancer. So how many patients received preoperative chemotherapy and for what reasons and were all those 
patients treated by chemo equally distributed in both groups?

Dr Yerokun. As far as preoperative chemotherapy, there were $3.2 \%$ of patients in the SBRT group that received preoperative chemotherapy versus $6 \%$ in the wedge resection group, so not equally distributed. However, we did not think that this difference contributed to the dramatic survival advantage associated with wedge resection.

Dr Weder. And my last question. Surgically treated patients were upstaged in $10.7 \%$. What were the consequences, adjuvant radiotherapy, adjuvant chemotherapy, conversion to lobectomy?

Dr Yerokun. We didn't look at all those endpoints, but we were able to see that in the patients who were upstaged, that $10 \%$ of patients that were upstaged, the 5-year mortality was about $40 \%$ in that cohort.

Dr Weder. I want to congratulate you again on this very important contribution.

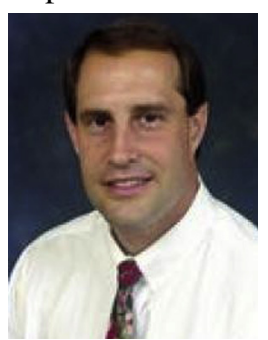

Dr R. Cerfolio (Birmingham, Ala). First of all, I love your message, congratulations, but I was very surprised you didn't look at pulmonary function tests. How could you not match the patients on the single best predictor of longevity from emphysema-the percent diffusing capacity of the lungs for carbon monoxide and percent forced expiratory volume in 1 second? Isn't that more than just a flaw in the database? Did I miss it in your abstract? Didn't you match them on pulmonary function tests?

Dr Yerokun. No, the NCDB does not capture pulmonary function tests.

Dr Cerfolio. That's a major problem. I am shocked it wasn't in the limitation slide. I mean, people are going to die from their pulmonary disease if they have a terrible percent forced expiratory volume in 1 second and percent diffusing capacity of the lungs for carbon monoxide, and you use survival as an endpoint. Obviously, most get SBRT for this reason and it is almost always pulmonary function tests. So you have got to mention that, number one.

Number two, the second problem I have is you used wedge resection as a surrogate of being an experienced surgeon. I would argue guys who are doing wedges are surrogates of guys who aren't particular good or experienced surgeons.

Any comments on that?

Dr Yerokun. The main reason for selecting wedge resection was because of its poor oncologic outcome, and we wanted to see whether the worst we had to offer as far as surgeons was better than SBRT.

Dr Cerfolio. No, I understand that, but you are using that as a surrogate of experienced surgeons. I would argue if you are doing more wedges, that is a surrogate of a less- experienced surgeon. You should have looked at segmentectomy and lobectomy as surrogate of an experienced surgeon.

\section{Thank you.}

Dr Yerokun. Thank you.

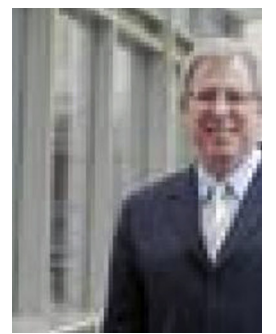

Dr M. DeCamp (Chicago, Ill). Congratulations, a great paper, and one that will help us tremendously as we debate our radiation oncology colleagues. One of the small points you made was the number of lymph nodes sampled in the wedge resection group, and of course our SBRT colleagues don't have any nodal staging. What percentage of the surgical patients actually had any nodes sampled? We know that a number of those wedge resections were done with no nodal staging. This gets at your point about whether the patients in both groups are truly different. One of the most common arguments I have with my radiation colleagues is that SBRT is based on clinical staging, computed tomography, and positron emission tomography and really underestimates the true pathologic stage that they are proposing to treat.

Dr Yerokun. Thank you for your comment. We didn't look specifically at how many patients had lymph nodes extracted or had any lymph nodes. That is a good point, though, and something we can look for in the future. But I think your comment is definitely true and that is the reason we wanted to investigate this.

Dr Decamp. You reported a range of one to four nodes sampled, but there is likely a sizable population that had zero, and I think our SBRT colleagues will tease that out and focus on it.

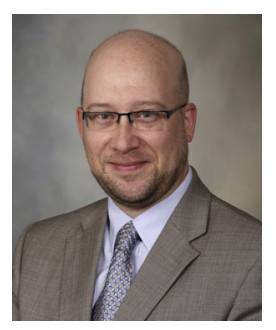

Dr S. Cassivi (Rochester, Minn). Notwithstanding the comments that my other colleagues have made, I think your talk is an excellent one and one that will be listened to and your paper will be read by many people. So it is important. And ironically Cerf did not make the sports analogy, but I will. No one tunes into the sports channel to hear the scores at the end of the first period or at the end of the half; they want to know the score at the end of the game. What you have produced is a paper that shows us the end of the game. Rather than the papers or the studies that are in process that provide us with outcomes at one or three years, you provide us with outcomes at five and beyond, which I think are the most pertinent. So you are to be commended on that.

My question to you is, with your innovative piece at the end about looking at the different centers and the percentage of SBRT that they do, why did you cut it off at 3 years? Why not at 5? Was it an issue of trying to power your study enough? Why did you cut it off at 3 ? 
Dr Yerokun. Good question and thank you for your comment. The reason we cut it off at 3 years was a statistical issue in terms of censoring. The median follow-up was slightly more than 3 years in both groups. So if we go further than that, then more than $50 \%$ of the patients would have been censored and then it would have been a powering issue. Three years was where we had the right amount of power to detect a difference without worrying about censoring.

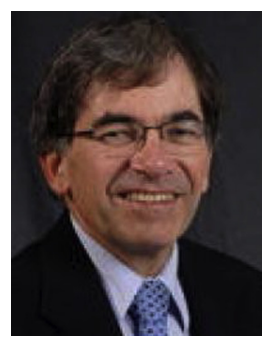

Dr T. Egan (Chapel Hill, NC). That was a nice presentation, but I'm afraid your data are pretty severely flawed, and this has nothing to do with the sports rivalry between UNC and Duke. But you have compared apples that got wedge resections to oranges that got stereotactic radiation therapy. We have been doing SBRT at UNC for a very long time, and our bias is to get patients to have surgical resections, and we offer SBRT to patients who are too sick to have wedge resections. So it is not at all a surprise that your long-term survival is worse with SBRT, and you absolutely need to look at disease-free survival. You already admitted that the patients with SBRT were older and they were likely sicker with more comorbidities and poorer pulmonary function tests.

So I don't think your results are at all surprising, and unfortunately it is only going to be with prospective, randomized, well-controlled studies that we will be able to answer this question.

Dr Yerokun. Thank you for your comment. I agree with you that really the best way to determine which one is better are randomized controlled trials.

As far as our analysis, we did limit the SBRT group to those that were deemed operable by their clinician. Although this is limited, it did remove a lot of those palliative patients. We also did a subgroup analysis of patients younger than 60 years with a Charlson-Deyo comorbidity score of 0 , and in that subgroup analysis there were 641 patients in the wedge resection group and 67 patients in our SBRT group. A survival advantage was still seen with the wedge resection group compared with the SBRT group. We propensity matched that group as well, and there were 57 patients in each group and we still saw a survival advantage with wedge resection.

Unfortunately, with the NCDB we do not have diseasefree survival, and the Charlson-Deyo comorbidity score was actually better in the SBRT group as opposed to the wedge resection group in the overall analysis.

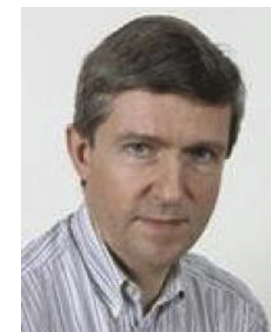

Dr P. Van Schil (Antwerp, Belgium). Thank you for this major contribution. I have one question. When we discuss with radiation oncologists, a hot item remains those patients who have local recurrent disease and come to salvage surgery for us. Do you have any idea how many of these patients who had SBRT had salvage surgery afterwards and what the results were?

Dr Yerokun. No, we didn't look at what happened to the SBRT group afterwards, but it is something we did talk about and something that would be interesting to follow up on. But thank you for your comment.

Dr Moon. Walter, one final question?

Dr Weder. I just want to echo, it will be an important contribution, and all the data we have so far comparing SBRT with surgery are of a retrospective nature with its limitation. However, I believe if you could refine your manuscript by integrating answers to these various questions, I think it will be a very important contribution.

Congratulations again.

Dr Yerokun. Thank you. 


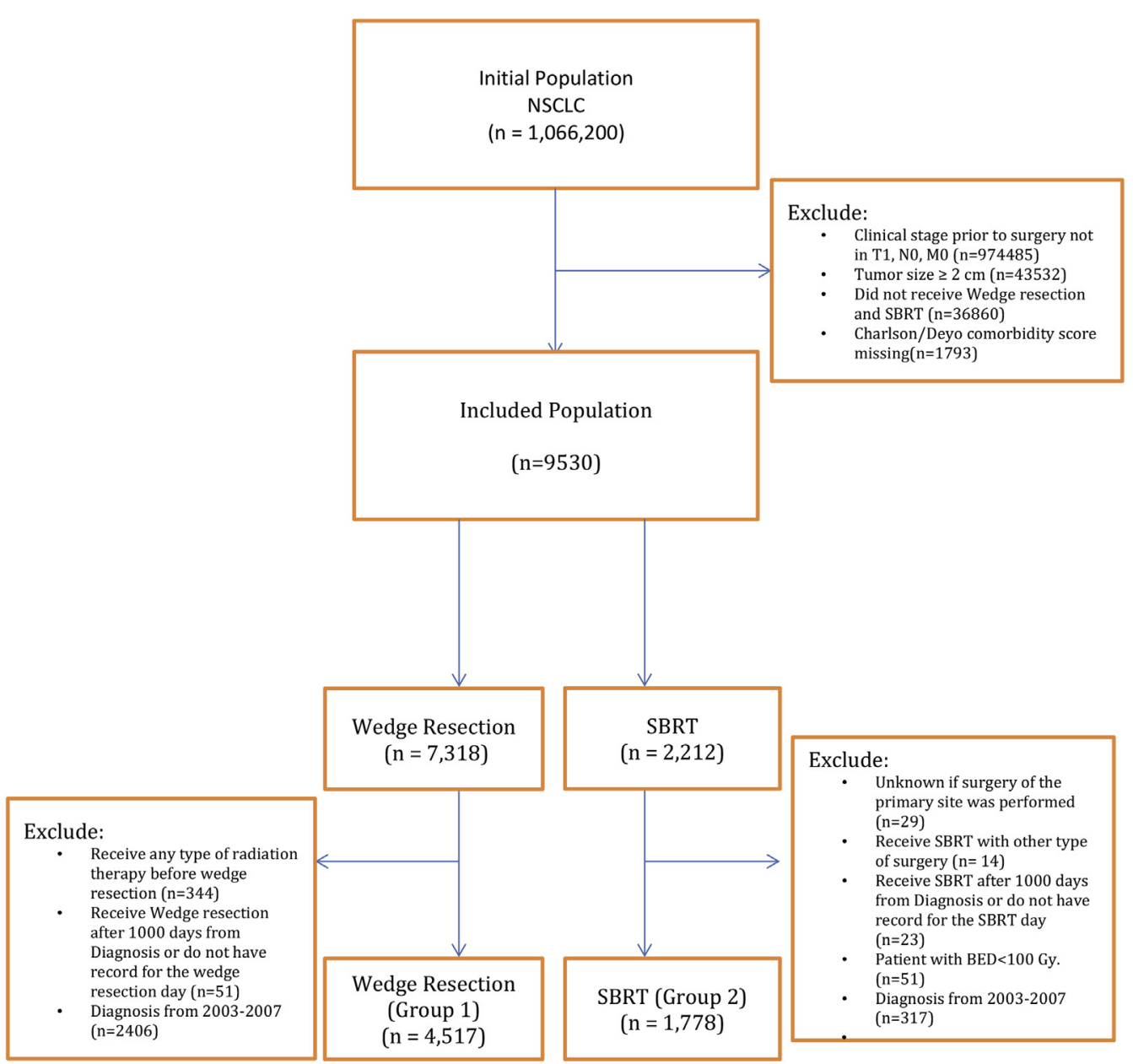

FIGURE E1. Strengthening the Reporting of Observational Studies in Epidemiology (STROBE) diagram. NSCLC, Non-small cell lung cancer; $S B R T$, stereotactic body radiotherapy; $B E D$, biologically effective dose. 


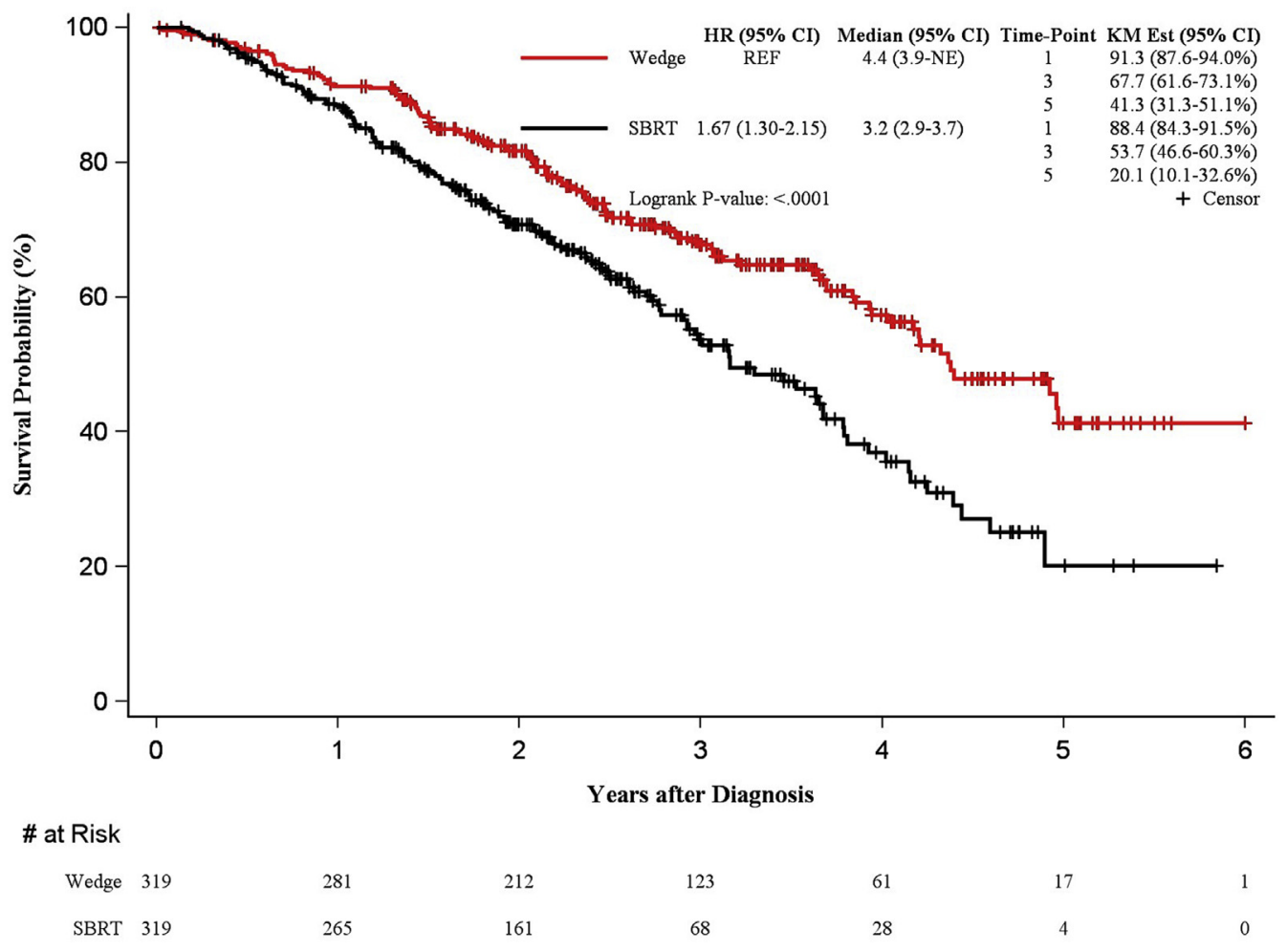

FIGURE E2. Age $>80$ years subgroup analysis. Kaplan-Meier-adjusted survival of patients with clinical-stage IA NSCLC. Overall survival of matched groups is shown. $H R$, Hazard ratio; $C I$, confidence interval; KM Est, Kaplan-Meier estimate; REF, reference group; NE, nonestimable; SBRT, stereotactic body radiotherapy. 


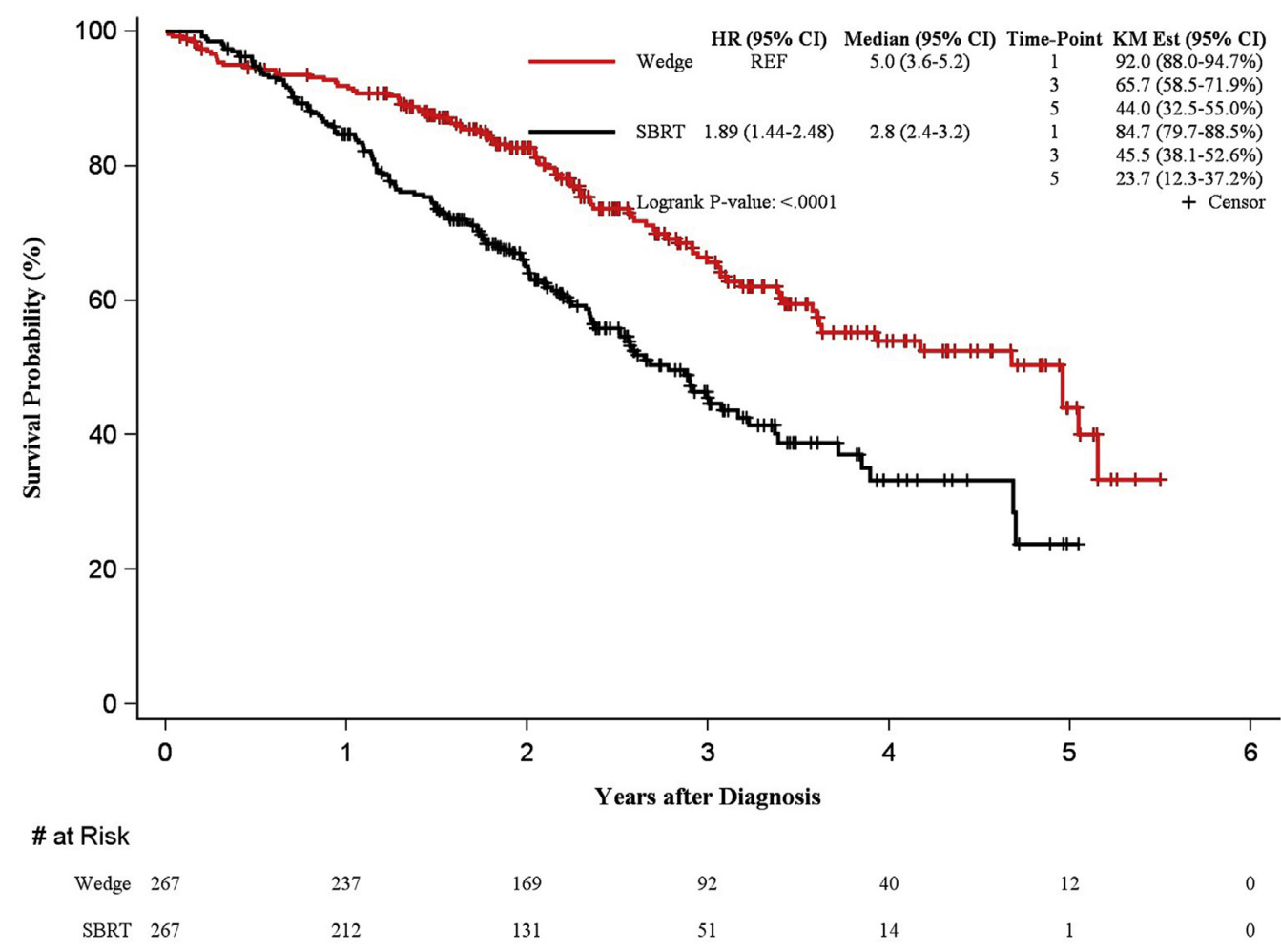

FIGURE E3. Charlson-Deyo score $\geq 2$ subgroup analysis. Kaplan-Meier-adjusted survival of patients with clinical-stage IA NSCLC. Overall survival of matched groups is shown. $H R$, Hazard ratio; $C I$, confidence interval; KM Est, Kaplan-Meier estimate; REF, reference group; SBRT, stereotactic body radiotherapy.

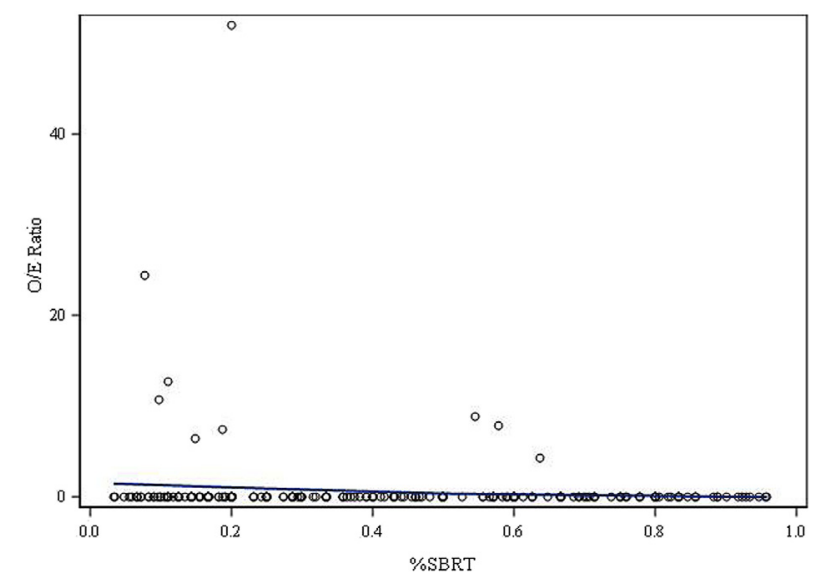

FIGURE E4. Center-level comparison of SBRT with wedge resection. Scatterplot is shown of centers stratified by their center ratio of SBRT/ wedge. First-quartile centers predominately used wedge resection, whereas fourth-quartile centers predominately used SBRT. Centers with either all SBRT patients, all wedge resection patients, or with less than 5 patients were excluded. Quartiles were compared with a ratio of observed mortality to expected mortality, with an $\mathrm{O} / \mathrm{E} \leq 1$ indicating similar or better performance than expected and an $\mathrm{O} / \mathrm{E}>1$ indicating worse performance than expected. Depicted is center 1-month mortality $\mathrm{O} / \mathrm{E}$ ratios. $O / E$, Observed to expected; \%SBRT, percent stereotactic body radiotherapy use. 


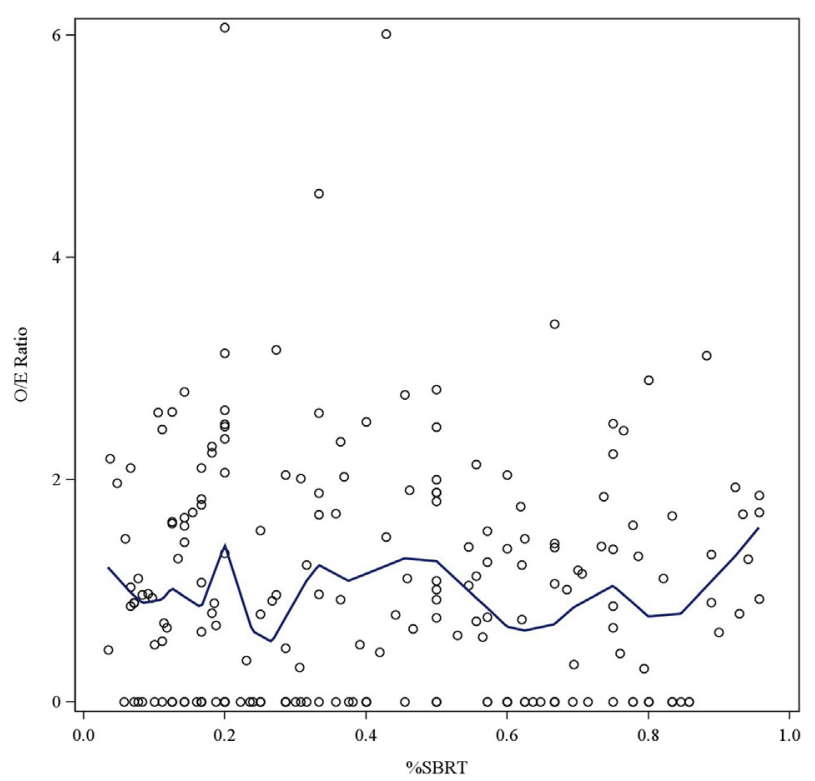

FIGURE E5. Center-level comparison of SBRT with wedge resection. Scatter plot is shown of centers stratified by their center ratio of SBRT/ wedge. First-quartile centers predominately used wedge resection, whereas fourth-quartile centers predominately used SBRT. Centers with either all SBRT patients, all wedge resection patients, or with less than 5 patients were excluded. Quartiles were compared with a ratio of observed mortality to expected mortality with an $\mathrm{O} / \mathrm{E} \leq 1$ indicating similar or better performance than expected and an $\mathrm{O} / \mathrm{E}>1$ indicating worse performance than expected. Depicted is center 1-year mortality $\mathrm{O} / \mathrm{E}$ ratios. $O / E$, Observed to expected; \%SBRT, percent stereotactic body radiotherapy use.

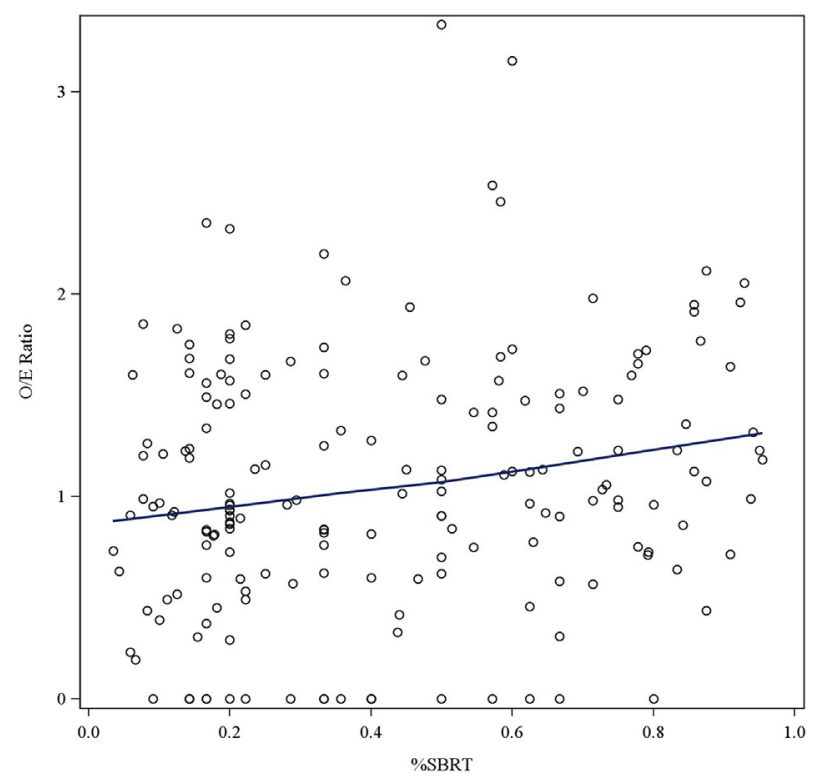

FIGURE E6. Center-level comparison of SBRT with wedge resection. Scatter plot is shown of centers stratified by their center ratio of SBRT/ wedge. First-quartile centers predominately used wedge resection, whereas fourth-quartile centers predominately used SBRT. Centers with either all SBRT patients, all wedge resection patients, or with less than 5 patients were excluded. Quartiles were compared with a ratio of observed mortality to expected mortality with an $\mathrm{O} / \mathrm{E} \leq 1$ indicating similar or better performance than expected and an $\mathrm{O} / \mathrm{E}>1$ indicating worse performance than expected. Depicted is center 2-year mortality O/E ratios. $O / E$, Observed to expected; \%SBRT, percent stereotactic body radiotherapy use. 